International Conference on SOCIAL SCIENCE, HUMANITIES \& EDUCATION

$21-23$ December, 2018 in Berlin - Germany

\title{
DEVELOPING THE MIXED METHOD MATHEMATICS INSTRUCTION MODEL FOR IMPROVING COGNITIVE LEARNING IN MATHEMATICS
}

\author{
Chaowarit Phanthong, Chatchai Tritham*, Noppadol Thumchuea \\ Muban Chombueng Rajabhat Univiversity, Thailand
}

First author: chatchai.tritham@ieee.org, Mobile: +66(0)642969333

\begin{abstract}
The study objectives were: 1 ) to study current states and problems of relevant primary students in developing mix method mathematics instruction model for improving cognitive learning in mathematics, and 2) to evaluate the effectiveness of model. The model was created and implemented with grade sixth students of primary schools, in Thailand, and compared with control group, provided in traditional approach. The research participants consisted of ninth school administrators, and ninth mathematics teachers who taught in 6th grade level in the academic year of 2018, from ninth schools in Chombung District, Ratchaburi Province, Thailand. The research instruments consisted of questionnaire on the problem of cognitive learning in mathematics; a case study of two-dimensional geometry. The collected data were analyzed by mean, percentage, mean and standard deviation (S.D). The model was designed through methodology of research and development, which was composed of: 1) principles and theoretical concepts, 2) learning objectives, 3) learning process, 4) social system, 5) principles of response, 6 ) the support system. The research findings were as follows: 1) mathematics learning problem, it was found that the sample agreed with the problem of learning mathematics, 2) the development of a mathematical course model, 3) multimedia and learning resources of the system can support the teachers, learners and parents.
\end{abstract}

Keywords: mathematics instruction model: active learning: creative thinking: cognitive learning 